\title{
The Evolvement of Automobile Steering System Based on TRIZ
}

\author{
Xinjun Zhao and Shuang Zhang \\ School of Mechanical Engineering and Automation, \\ Northeastern University, \\ Shenyang city, P.R. China \\ \{Xinjun.Zhao, Shuang.Zhang,xinjun_zhao\}@126.com
}

\begin{abstract}
Products and techniques pass through a process of birth, growth, maturity, death and quit the stage like biological evolution process. The developments of products and techniques conform to some evolvement rules. If people know and hold these rules, they can design new kind of products and forecast the develop trends of the products. Thereby, enterprises can grasp the future technique directions of products, and make product and technique innovation. Below, based on TRIZ theory, the mechanism evolvement, the function evolvement and the appearance evolvement of automobile steering system had been analyzed and put forward some new ideas about future automobile steering system.
\end{abstract}

Keywords: Product innovation, mode of the technique system evolution of TRIZ, steering wheel.

\section{Introduction}

With the process of economic globalization, corporations compete more and more seriously. It's technique innovation that boosts the product innovation directly. It will come to the point for corporations that how to forecast and develop the next generation of products accurately, and make product and technique innovation to obtain the powerful tools in the competitions winning.

\section{The Evolution Theory of the Technique Systems of TRIZ}

Among the increasing advanced technology and design theories and methods, TRIZ has become to one of the most important theories of technique innovation solving and technique forecasting, which have been paid close attention to by corporations both here and abroad. It provides a scientific method for corporations to analyze and grasp the technique directions of products.

TRIZ is a Russian abbreviation. It means "The Theory of Inventive Problem Solving”. G. S. Altshuller who is an inventor from Russian founded TRIZ in 1946. TRIZ is a kind of systemic methodology which is based on knowledge and face to people to solve inventive problems. Some west countries such as the USA and German have 
called TRIZ "alchemy". With the fore-Russia's disassembly, TRIZ is widely applied in engineering technique field out of military affairs, and it is spread to multinational corporations. 80 percents of global 500 strongest corporations use TRIZ to some extent in product development. Thousands of great inventions are invented at tremendous speed.

Altshuller find that the developments of product and its technique always conform to some external rules, and the same rule usually be used again and again in different fields. Products betterment and techniques innovation pass through a process of birth, growth, maturity, death and quit the stage like biological system, and they conform to some rules. If people hold these rules, they can design products and forecast the trends of products on theirs own.

One part of hard core of TRIZ is evolution principle (rules) of technique system. According to its rules, it can forecast the trends of the products and techniques, and help corporations to develop new competitive products. The evolution rules of technique system of TRIZ include increasing idealization rule, system integrality rules, energy transmission rule, increasing system dynamization and controllability rule, subsystem nonconforming evolution rule, promoting to super system rule, promoting to micro system rule, system coordination rule, technique system segmentation rule, system developing to multifunction and generalization rule, and changing substance construction rule, and so on. These rules basically contain evolution rules of main techniques of various products. And every rule has its concrete modes and courses. It's obvious that if engineer or technicians hold the rules (modes and courses), and they can affirm in which stage the products is and find products bugs and problems, and then forecast the trends of products and layout products development stratagem to develop new generation of products.

\section{The Evolvement of Automobile Steering System}

Automobile was invented more than 100 years ago. As an important part of automobile, automobile steering system was created with automobile evolution in the configuration, function and appearance aspect.

An integrated automobile steering system contains control mechanism, steering gearing and drive gearing. The steering control mechanism consists of steering wheel, steering shaft and column tube. Its function is to transfer power from the driver on steering wheel to the redirector; there are two kinds of steering gearing-mechanical steering gearing and power steering gearing. And the power steering gearing includes hydraulic transmission and pneumatic transmission.

\subsection{The Mechanism Evolvement of Automobile Steering System}

Along with the development of automobile technique and performance itself, automobile steering system needs to be innovated by increasing system dynamization and controllability step by step. In order to be adapt to the mutative environments, it comes to the point for the steering system that how to increase its flexibility and changeability. 
In early times when automobile was just invented, the driver turned a handle or a rail with a steering shaft in his hand to drive. The automobile had a pinion-rack steering gearing, which was the earliest ancestor of automobile steering gearing. The ratio of steering gearing was 1 to 1 . It needed much power to drive. When automobile prepositive engine were developed in 1891, the weight of the head of automobile was increased, thus steering system vibration might be transferred to the driver by turning handle or rail, and it made the driver feel too tired. As a single-hinge mechanism, the original handle or rail with a steering shaft should be improved, and its flexibility should be increased to avoid the disadvantage.

Considering the viewpoint of the technique system evolution principle of TRIZ, for the sake of avoiding the above disadvantage, increasing hinges can be used here in the course of "increasing flexibility" evolution (of the "increasing system dynamization and controllability rule"). Automobile steering system evolution actually conforms to the course. Multi-hinge mechanism naturally increases degree of freedom and controllability, avoiding vibration.

In the evolution of automobile steering system, Eliot-steering elements in which two front wheels substitute shaft drive is applied firstly; pinion-rack steering gearing design went to theorization later, and it was processed precisely, thus pinion-rack steering gearing is applied in automobiles formally. With automobile techniques improving themselves, automobile steering system also developed rapidly. Parallel link mechanism patent was got, and was improved to echelon link mechanism soon, which had approached to modern integrated automobile steering technique. Parallel link mechanism had a vertical hinge which fixed attachments of steering shaft and wheels with bodywork. There was a tie-bar which connected the attachments of steering shaft one another. A special steering rack controlled the tie-bar moving to the right and left, and made the inner wheel and outer wheel turn. The mechanism with a gear reducer made the automobile system more flexible to control, and insulated vibration. The handle and rail were replaced by circular steering wheel. And the circular steering wheel with a steering shaft moved to the right or left. The former vertical fixing had developed to gradient fixing for both steering wheel and steering shaft.

The flexibility and controllability of automobile steering system was innovated continuously with the automobile technique renovation, and they were improved better and better. Mechanical steering gearings trend to diversification such as pinionrack gearing, worm gearing, and circular ball gearing. However, mechanical steering gearings have disadvantage themselves. The disadvantage of pinion-rack gearing is that the precision of rack is hard to control and it tends to be wore and tore. For the worm gearing and circular ball gearing, moment output is large, but volume is even too large and configuration is too complex. Therefore power steering gearing break a new path avoiding the disadvantage of traditional mechanical steering system. It's popular for automobile manufacturer and owners. In America power steering gearings were applied in some limousines in 1950s. It depends on the engine driving the hydraulic which provide hydraulic pressure, and the pressure is put to the movable organs which are connected to the steering shaft. This system greatly debases the fatigue of control mechanism. Because of the higher working pressure and sensitivity, as well as the smaller size, hydraulic power transmission is applied widely.

Before long, with a view to the medium of energy transmission, pneumatic power transmission comes forth. It depends on the engine driving the pneumatic pump which 
provides pneumatic pressure, and the pressure is put to the movable organs which are connected to the steering shaft, then it helps driver who has unequal power to turn right or left.

It can be concluded from the process above that automobile steering system develops by the following course:

(1) single-hinge mechanism;

(2) multi- hinge mechanism of parallel link steering system;

(3) hydraulic power transmission;

(4) pneumatic power transmission.

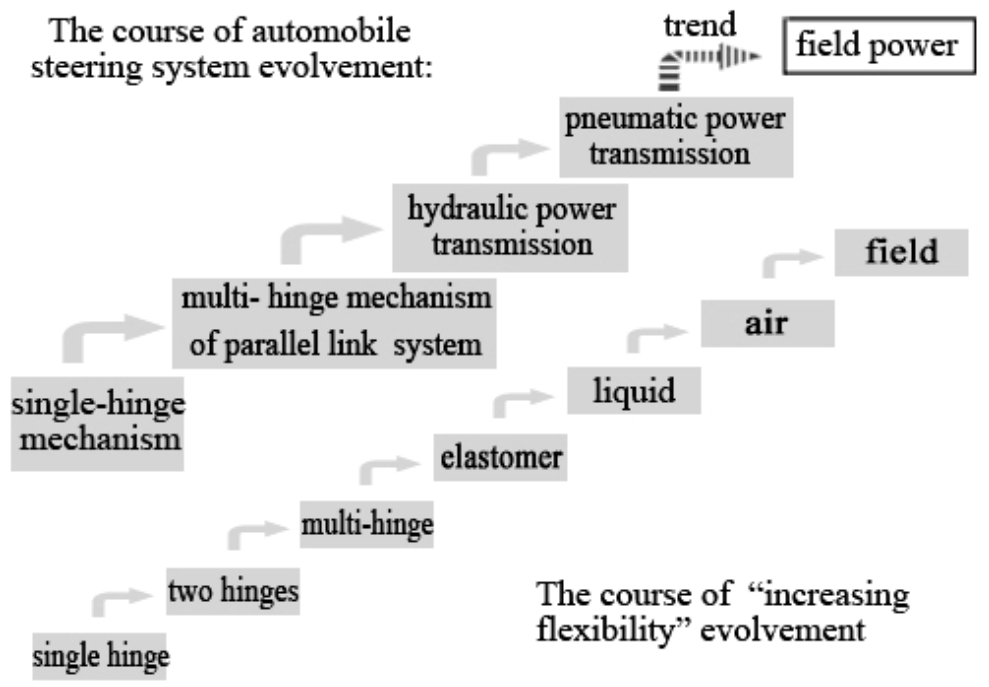

Fig. 1. The course of automobile steering system evolvement

Compare with the course of "increasing flexibility" evolvement, the course of automobile steering system evolvement accords to the former course to some extent from the above Fig.1. According to the course of "increasing flexibility" evolvement, it is conjecturable that steering system depending on "filed power" will be developed in the near future.

\subsection{The Function Evolvement of Automobile Steering System}

One of the modes of the technique system evolution of TRIZ is that a system trends to integrate multi functions, and then try to condense itself. The functions of a technique system always trends to complication firstly by increasing the amount of organs and improving functional characteristics, and sequentially condense itself.

In early times, the systems of handle or rail with a steering shaft are all simple, and they only have the function of turning right or left. Later electric loudspeaker was applied in automobiles, and it was fixed in the steering wheel. In the 1950s, the idea of security air chamber was designed. By the 1980s, the security air chamber for 
protecting drivers was applied in automobiles. It was in the centre of the steering wheel. After 1990, the functions of steering wheel trend to diversification. Some accessional functions are added where the thumb can touch in the steering wheel. The advantage of the multi-function steering wheel is that drivers needn't to move in so much room, and they can control the automobile conveniently for many functions (Fig.2 shows the steering wheel of some kinds of automobile. To our surprised, the conceptional steering system without steering wheel is showed to the world (Fig.3 is a concept). It only uses a gearlever (Fig.4) to turn right or left. The driver controls the automobile for all functions by an electric control system including some keystrokes.

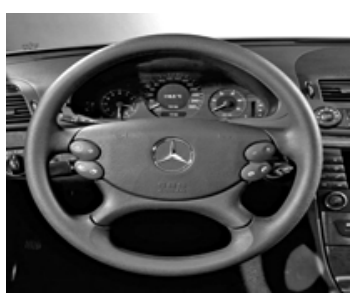

Fig. 2.

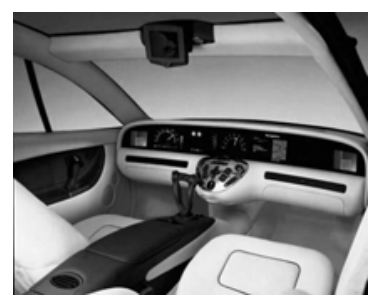

Fig. 3.

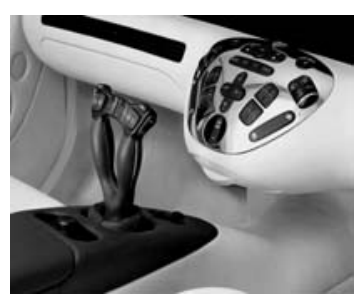

Fig. 4.

From the handle or rail steering system to multi-function steering wheel, and then developing to conceptional system without steering wheel, it is right a process from simple system to complex system, and then developing to simple system. It also shows that TRIZ technique system evolution rules are significant. The bi-system of gearlever and electric control substitute the former multi-function steering system. This idea comes from the method of TRIZ evolution mode -- developing a bi-system or multi-system instead of former single system.

\subsection{The Appearance Evolvement of Automobile Steering Wheel}

In early times, there were two kinds of appearances of automobile control mechanism. They were simple handle (Fig.5) and two rails crossed (Fig.6). The ideas came from the steering wheel of steamboat (Fig.7). After 1986, the appearance of automobile control mechanism was basically finalized for the steering wheel. It fixed a wheel around the rails. It made the structure much more firm (Fig.8). It could be called that two-wheel four spokes steering wheel (Fig.9) had ever been fixed in some kind of automobile in 1930s. It added another small wheel on the spokes of normal steering wheel. This kind of steering wheel was usually used in larger automobiles. For the size of wheel was larger, adding another wheel could make it more firm. The spokes in the wheel of automobile were transformed itself to several forms, such as four spokes ones, three spokes ones (Fig.10), two spokes ones, and trapeziform spoke ones (Fig.11). By the 1980s, the security air chamber for protecting drivers was applied in automobiles. And it enlarged the size of steering wheel centre. But the basically appearance of steering wheel didn't change. 


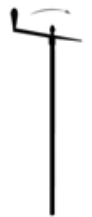

Fig. 5.

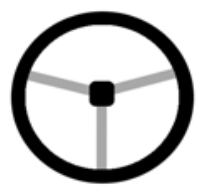

Fig. 10.

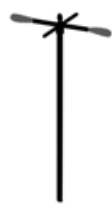

Fig. 6.

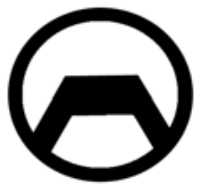

Fig. 11.

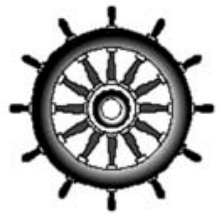

Fig. 7.

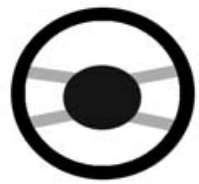

Fig. 12.

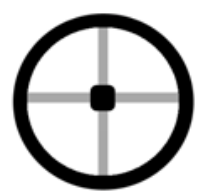

Fig. 8.

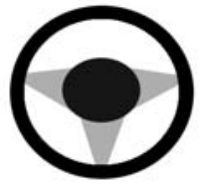

Fig. 13.

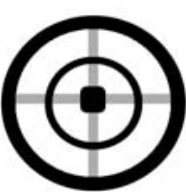

Fig. 9.

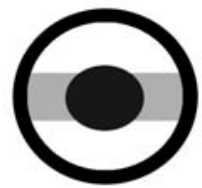

Fig. 14.

After 1990, four spokes (Fig.12) and three spokes steering wheels (Fig.13) are widely used. And there are also two spokes ones (Fig.14). The differences from Fig.1 to Fig.14 are some ideas coming out in spokes as well as the connection between spokes and wheels. In the TRIZ evolution mode of "technique system segmentation", there is a method to innovation. It is degenerating connection in segmenting course. Central controlling steering wheel is an example (Fig.15, Fig.16). Its spokes are separated from the centre of the steering wheel. The connection between spokes and centre is degenerated by another form. When a driver turns the steering wheel, only the wheel and its spokes turn round and the centre keep immovable. Thus the driver can conveniently push the buttons in the centre. And errors are avoided. The design of this kind of steering wheel is based on the man-machine engineering science. To some extent, it innovates on steering wheel appearance.

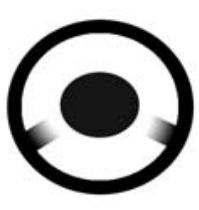

Fig. 15.

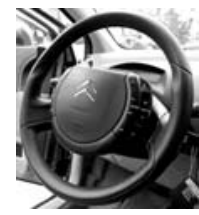

Fig. 16.

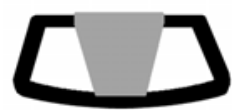

Fig. 17.

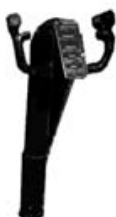

Fig. 18.

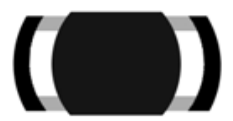

Fig. 19.

The steering wheel appearance reforms with the technique development. According to the "technique system segmentation rule" of TRIZ, technique systems are always innovated themselves by segmenting. One method is segmenting the system to several parts of simple shapes. The design of automobile steering wheel makes use of TRIZ method and works out various appearances of different forms. Lots of fashionable appearances are designed and applied in the conception automobiles. For example, some ideas (Fig.17) come from the U bar (Fig.18) of airplane controlling; another one is central controlling steering wheel mentioned above; and other one is 
wheel-incised steering wheel (Fig.19 and Fig.20) and sector steering wheel (Fig.21); the gearlever (Fig.22) in the non-wheel system of some conception automobile makes drastic change from the former appearance of steering wheel. It's the result that appearance changes along with product function. And the appearance follows the segmentation method. It changes to triangle with two balls above. On the ball there are several function buttons.

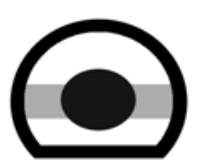

Fig. 20.

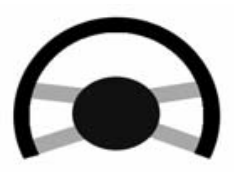

Fig. 21.

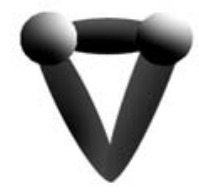

Fig. 22.

The appearance of automobile steering wheel evolves itself like it is described above. Although there's no wheel in some conception automobile, wheel is replaced by a gearlever. It has the same function to turn around using a new steering form which is applied in the new steering system. It may be a trend of steering wheel development in the future. Wheel in an automobile might be replaced, but basic turning function won't change; the chief aim of personal security won't change; the manmachine engineering science which is based on the relation human-machineenvironment will be applied better and better, and this idea won't change. New forms will be come out along with new techniques development, and they will be also innovated along with new requirements of human beings. Thus new steering system will naturally evolve on appearance.

\section{Conclusion}

While the trend of economy globalization turns to more serious, the competition among the corporations becomes more serious, too. It makes the corporations realize that it isn't enough at all to rely on the existing products and techniques. Not to advance is to go back. It is the innovation that could keep the corporations more competitive. Not only do the corporations need to know the existing condition of product technique but also the trends in the future. Thereby how to analyze the evolvement of products and technique has become more and more significant. It will give strong support to the course of products and technique innovation, and they can eventually develop new products that be satisfied by the clients.

\section{References}

1. Savransky, S.D.: Engineering of Creativity, pp. 5-8. CSC Press, New York (2000)

2. Tan, R.H.: Innovation Design-TRIZ: Invention Problem Solving Theory, pp. 15-20. Mechanic Industry Press, Beijing (2002) (in Chinese)

3. Mann, D.: Using S - Curves and Trends of Evolution in R\&D Strategy Planning. The TRIZ Journal 7, 56-64 (1999) 
4. Petrov, V.: The Laws of System Evolution. The TRIZ Journal 3, 9-17 (2002)

5. Zhao, X.: Technical Innovation Theory (TRIZ) and Its Application, pp. 144-1190. Chemical Industry Press, Beijing (2004) (in Chinese)

6. Auto home, http://www . autohome.com.cn

7. Auto Sohu, http: //auto.sohu.com 